(2) Open Access Full Text Article

REVIEW

\title{
Improving Collateral Circulation: A Potential Adjunctive Strategy to Prevent or Slow the Progression of Vascular Dementia
}

\author{
Baoyu Wei' \\ Zhaoqi Wang' \\ Shihao $\mathrm{Wu}^{\prime}$ \\ John Orgah' \\ Jinqiang Zhu' \\ Wanshan Song ${ }^{2}$
}

'State Key Laboratory of ComponentBased Chinese Medicine, Institute of Traditional Chinese Medicine, Tianjin University of Traditional Chinese Medicine, Tianjin, 301617, People's Republic of China; ${ }^{2}$ Department of Acupuncture and Cerebropathy, Second Affiliated Hospital of Tianjin University of Traditional Chinese Medicine, Tianjin, 300250, People's Republic of China

Correspondence: Wanshan Song; Jinqiang Zhu

Email sws19870604@I63.com;

zhujinqiang1860@163.com

\begin{abstract}
Vascular dementia (VaD), a cognitive disorder caused by cerebrovascular pathologies, is the most common cause of dementia in the elderly, being second only to Alzheimer's disease. Researches have shown that adequate cerebral blood flow (CBF) is the first condition for maintaining the structural integrity and normal function of the brain, and $\mathrm{VaD}$ is generally considered to be resulted from neuronal loss due to reduced $\mathrm{CBF}$. Collateral circulation, a compensation mechanism for $\mathrm{CBF}$, provides an alternative vascular pathway for blood to reach ischemic tissues, which has been confirmed to be associated with better clinical outcomes of ischemic diseases. At present, considerable effort has been devoted to enhancing the functional prognosis of acute ischemic stroke by improving collateral circulation. Since ischemic stroke is the primary contributor to $\mathrm{VaD}$, it is necessary to explore whether improving collateral circulation is beneficial to prevent or slow the progression of $\mathrm{VaD}$. This article reviews the compensatory characteristics of different levels of cerebral collateral circulation, addresses the relationship between collateral circulation and $\mathrm{VaD}$, and highlights that improving collateral circulation may be a potential adjunctive strategy in preventing and slowing the progression of $\mathrm{VaD}$.
\end{abstract}

Keywords: vascular dementia, cerebral blood flow, collateral circulation, pathology, precaution, palliation

\section{Introduction}

Vascular dementia (VaD), a term used to describe neurocognitive disorder, is widely regarded as a major contributor to the dementia after Alzheimer's disease. ${ }^{1}$ Epidemiology shows that $\mathrm{VaD}$ accounts for at least $20 \%$ of dementia cases worldwide, and even reaches $30 \%$ in Asia and developing countries. ${ }^{2} \mathrm{VaD}$ results from different vascular etiologies such as cerebral atherosclerosis/artery damage, thrombosis, vascular stenosis, or occlusion, which damage blood vessels in the brain and reduce cerebral blood flow (CBF), leading to secondary focal neuronal injury and tissue loss. ${ }^{3}$ Although the human brain is only $2-3 \%$ of the body mass, its metabolism is vigorous, consuming up to $20 \%$ of the total amount of oxygen and glucose contained in the blood. ${ }^{4,5}$ However, the amount of adenosine triphosphate stored in the brain is limited, so it must rely on the oxygen and nutrients delivered by the $\mathrm{CBF}$ to produce energy. ${ }^{6,7}$ When chronic hypoperfusion occurs in brain tissue, the rapid decline of $\mathrm{CBF}$ causes ischemia, hypoxia, and a series of injuries: (1) Hypoxia-induced oxidative stress leads to mitochondrial dysfunction, which directly damages neurons. ${ }^{8}$ (2) Oxidative stress also causes an imbalance in the ratio of 
antioxidants and reactive oxygen species to damage vascular endothelium, glial and neurons, which leads to endothelial dysfunction, neurovascular decoupling, induced thrombosis and vasospasm, eventually narrowing the blood vessels and further reducing $\mathrm{CBF}^{8,9}$ (3) Chronic cerebral hypoperfusion $(\mathrm{CCH})$ is extremely prone to damage the periventricular white matter (WM), basal ganglia and hippocampus, leading to cognitive impairment. ${ }^{10}$ In summary, the continuous reduction of CBF aggravates cerebral ischemia-hypoxic damage, leads to neuronal death and cognitive decline, and ultimately contributes to the occurrence and development of VaD. ${ }^{11}$ Therefore, adequate $\mathrm{CBF}$ is a primary condition for maintaining the structural integrity and normal function of the brain, ${ }^{7}$ and improving CBF may be an effective strategy for the prevention and treatment of $\mathrm{VaD}$.

Collateral circulation is defined as a subsidiary network of vascular channels that provide nutrient perfusion to ischemic areas when the principal conduits cannot stabilize $\mathrm{CBF}^{12}$ In recent years, there has been accumulating evidence that collateral circulation is associated with the protection of ischemic brain injury. ${ }^{13-15}$ Enhancing collateral perfusion as an adjunctive strategy combined with thrombolysis and endovascular interventions is considered to play a potentially important role in the treatment of acute ischemic stroke. ${ }^{16}$ As we all know, ischemic stroke (IS) is a major risk factor for $\mathrm{VaD}$, and its incidence impairs cognitive function. ${ }^{17}$ However, the benefits of collateral blood flow in cognitive function are not fully understood, so few studies have focused on its effect on VaD. In this review, we summarize the relationship between collateral circulation and the common pathological or pathophysiological conditions in the course of $\mathrm{VaD}$, and concentrate on the potential contribution of improving collateral circulation in preventing and slowing the progression of $\mathrm{VaD}$.

\section{Different Levels of Collateral Circulation and Its Compensation Characteristics}

Collateral circulation in the brain is usually divided into primary routes, ie, the Circle of Willis, secondary routes, eg, collaterals from the external to the internal carotid artery and leptomeningeal collaterals, ${ }^{18}$ and tertiary routes, eg, arteriogenesis and angiogenesis. ${ }^{19}$ The Circle of Willis, as the main form of arterial compensation, provides immediate diversion of $\mathrm{CBF}$ to ischemic regions through existing anastomoses, which generally occurs after the sudden thrombotic occlusion of the internal carotid artery. ${ }^{20}$ However, substantial variability exists in the size and degree of completeness of the Circle of Willis, and a complete circle is only in $42-52 \%$ of population. ${ }^{21}$ Secondary collaterals are presumed to be recruited once primary collaterals at the circle of Willis is insufficient to meet the need; for example, in the case of embolic occlusion of the middle cerebral artery, leptomeningeal anastomoses become the principal alternative pathways to supply blood flow. ${ }^{22}$ If the secondary compensation is still insufficient, arteriogenesis and angiogenesis may begin to operate. Arteriogenesis can compensate for CBF not only acting in time but also more efficiently compared to angiogenesis that occurs in a delayed fashion, while increases the total resistance of the vascular bed of the affected territory. ${ }^{23}$

\section{Relevance of the Collateral Circulation to VaD Collateral Circulation and Atherosclerosis}

Different from a single disease, $\mathrm{VaD}$ is a group of conditions with different pathological correlates, which involve different forms of cerebrovascular diseases, mainly including macrovascular diseases, and small vessel diseases (SVD). ${ }^{24}$ Atherosclerotic stenosis of large arteries causes macroinfarction, infarction of major arterial territories due to atherosclerotic thromboembolism and induces major stroke, while lacunar infarcts, microinfarcts and WM hyperintensities are mostly explained by progressive $\mathrm{SVD}^{3}$ Atherosclerosis of the large arteries or SVD accounts for most of the burden of $\mathrm{VaD}$ and affects cognitive function. ${ }^{25,26} \mathrm{~A}$ recent crosssectional study provides more evidence of a positive correlation between intracranial atherosclerotic stenosis and cognitive impairment after stroke. ${ }^{27}$ Collateral circulation may counteract the potentially adverse effects of stenosis. In the study of systematic evaluation of collaterals on angiography in Warfarin-Aspirin Symptomatic Intracranial Disease, it was found that collateral circulation is often observed with intracranial atherosclerosis at varying extents, and the extent of collateral flow is correlated with the percentage of stenosis, with more severe stenoses exhibiting greater compensation via collaterals. $^{28}$ In another retrospective cohort study of patients with symptomatic intracranial stenosis and compromised antegrade flow, the results of composite flow assessment also showed that good collateral circulation was associated with favorable neurological outcomes. ${ }^{29}$ 


\section{Collateral Circulation and $\mathrm{CCH}$}

$\mathrm{CCH}$, caused by SVD and atherosclerosis, is regarded as a major factor leading to cognitive decline and the degenerative process of $\mathrm{VaD}^{30}$ In essence, $\mathrm{CCH}$ deprives oxygen and nutrients, ultimately leading to synaptic dysfunction and neuronal degeneration/loss. ${ }^{31}$ $\mathrm{CCH}$ may stimulate the recruitment and regeneration of collateral circulation. In rats with bilateral common carotid artery occlusion, $\mathrm{CCH}$ promoted angiogenesis that paralleled recovery of blood flow in the later stage (from 4 to 6 weeks) of surgery. ${ }^{32}$ Ipsilateral leptomeningeal collateral growth was observed in normotensive rats with unilateral common carotid artery occlusion. ${ }^{33}$ Furthermore, clinically, due to $\mathrm{CCH}$, cervical atherosclerosis may promote more extensive collateral circulation in patients with IS. ${ }^{34,35}$ Effective collateral flow in carotid atherosclerotic stenosis patients was associated with the normalisation of territory arterial spin labelling perfusion territory after carotid endarterectomy. ${ }^{36}$

\section{Collateral Circulation and Hemodynamic Impairment}

Hemodynamic impairment is an important sign of cognitive decline and plays an important role in the process of $\mathrm{VaD}^{37} \mathrm{~A}$ meta-analysis of transcranial Doppler studies on cerebrovascular hemodynamics in VaD showed that hemodynamics in patients with $\mathrm{VaD}$ had a significant disturbance, compared with healthy elderly subjects. ${ }^{11}$ Collateral circulation has a significant influence on hemodynamic status. ${ }^{38}$ In the case of symptomatic intracranial atherosclerotic stenosis, the fractional flow at the lesion in patients with poor collateral circulation was associated with the percentage of stenosis at the lesion, and conversely, with good collateral circulation was not related to the percentage of stenosis. ${ }^{39}$ In addition, improvement of collateral blood flow contributed to the improvement of increased oxygen extraction fraction in patients with carotid occlusion and no interval stroke during the hemodynamic impairment. ${ }^{40}$

\section{Collateral Circulation and WM Lesions}

Diffuse and focal WM lesions are a feature of $\mathrm{VaD}$, which involves myelin loss, axonal abnormalities, arteriolosclerosis, and parenchymal changes resulting from lacunar infarcts, microinfarcts, microbleeds and perivascular spacing. ${ }^{41,42}$ Diffuse and focal WM changes are described in neuroimaging as WM hyperintensities
(WMH) on T2-weighted MRI or leukoaraiosis (LA) on computed tomography. ${ }^{43}$ LA typically affect the prefronto-subcortical circuits, which may be responsible for some of the cognitive deficits usually associated with executive function. ${ }^{44}$ Poor collateral circulation of periventricular WM combined with diffuse cerebral ischemia seems to be the cause of LA, and poor recruitment of collaterals is also associated with $\mathrm{WMH}^{45,46}$ Studies have shown that the severity of LA is linked to poor collateral grade, and good collateral grade is independently associated with reduced LA volume. ${ }^{47}$

\section{Collateral Circulation and Cognitive Dysfunction}

The cognitive dysfunction of $\mathrm{VaD}$ is usually manifested as memory loss, attention, executive dysfunction, and so on. ${ }^{48}$ The regulation of CBF may affect cognitive function. ${ }^{49}$ Despite collateral circulation compensated for reduced CBF, its effect on cognitive function remains controversial. ${ }^{50,51}$ Recent studies have shown Prostaglandin E1 treatment can enhance $\mathrm{CBF}$ recovery in $\mathrm{CCH}$ by dilating blood vessels and sustaining angiogenesis, which is associated with the alleviation of cognitive impairment in bilateral CCA occlusion rats. ${ }^{52}$ Chronic remote limb ischemic conditioning may improve long-term $\mathrm{CBF}$ and long-term cognitive and motor functions by inducing angiogenesis and collateral remodeling. ${ }^{53}$ In addition, a prospective cohort, cross-sectional, single-center study provided more evidence that, during the two-year follow-up period, patients who had severe middle cerebral artery stenosis with "moderate" and "poor" leptomeningeal collateral status had function impairment in at least one cognitive domain, but for patients with "good" leptomeningeal collateral status, the cognitive function was not significantly affected. ${ }^{54}$ Another clinical study has reported that anterior communicating artery collaterals may benefit the selective attention function of patients with severe internal carotid artery. ${ }^{55}$

\section{Potential Contribution of Improving Collateral Circulation in the Course of $\mathrm{VaD}$ Good Prognosis of IS Reduces the Risk of $\mathrm{VaD}$}

Stroke can increase the risk of $\mathrm{VaD}$ that has been widely discussed. ${ }^{56}$ IS, a typical risk factor for $\mathrm{VaD}$, accounts for $87 \%$ of all strokes worldwide. ${ }^{57}$ There is evidence that $25-$ $30 \%$ of IS survivors will develop VaD immediately (within 
three months after stroke) or delayed (more than three months or after recurrent stroke). ${ }^{58}$ So, the prevention and management of IS are obviously expected to reduce the burden of $\mathrm{VaD}$. At present, studies have confirmed that good collateral circulation can prolong the treatment time window of IS by slowing the loss of penumbra tissue, and decrease the risk of hemorrhagic transformation. ${ }^{59}$ Collateral circulation may also help in delivering more tissue plasminogen activator to the position of occlusion, resulting in improved recanalization. ${ }^{60}$ Furthermore, collateral circulation has been shown to be an important determinant of cortical infarct volume, and good or better collateral circulation can alleviate the injury of hypoperfusion and reduce the infarct volume. ${ }^{61,62}$ Therefore, pretreatment of the collateral state is conducive to maintain the penumbra before recanalization, inhibit the growth of the infarct core area and increase the success rate of recanalization to enhance the prognosis of IS to prevent IS from inducing VaD. ${ }^{13,63,64}$

\section{Improvement of Pathological Conditions Slows the Progression of $\mathrm{VaD}$}

So far, there are still no FDA approved treatment options for VaD. Although measures such as blood vessel expansion, anti- thrombosis, anti-platelet aggregation, anti-oxidation, and enhancement of cholinergic have shown a certain extent of therapeutic effect, they are far from satisfying the needs of patients. ${ }^{65}$ A review of the above-mentioned convincing literature undoubtedly shows that collateral circulation is strongly associated with atherosclerosis, $\mathrm{CCH}$, hemodynamic impairment, WM lesions and cognitive dysfunction, which are common in the pathophysiology of $\mathrm{VaD}$. Not only that, it also suggests that good collateral circulation may have a positive effect on the fate of these typical pathological conditions of $\mathrm{VaD}$. Therefore, we speculate that enhancing collateral circulation may slow the progression of $\mathrm{VaD}$ via improving related pathological states and promoting CBF recovery to protect neurons and cognitive function. There is evidence that in the case of reduced tissue perfusion, inhalation of nitric oxide improves collateral blood flow by dilating cerebral resistance vessels, thereby significantly reducing ischemic brain injury and transforming into significantly improved neurological outcomes. ${ }^{66}$ Of course, merely enhancing collaterals may not be enough to completely save neuron loss and cognitive deficits after permanent ischemia. It may be used as an auxiliary strategy, combined with other strategies to produce cumulative effects in a synergistic form of treatment.

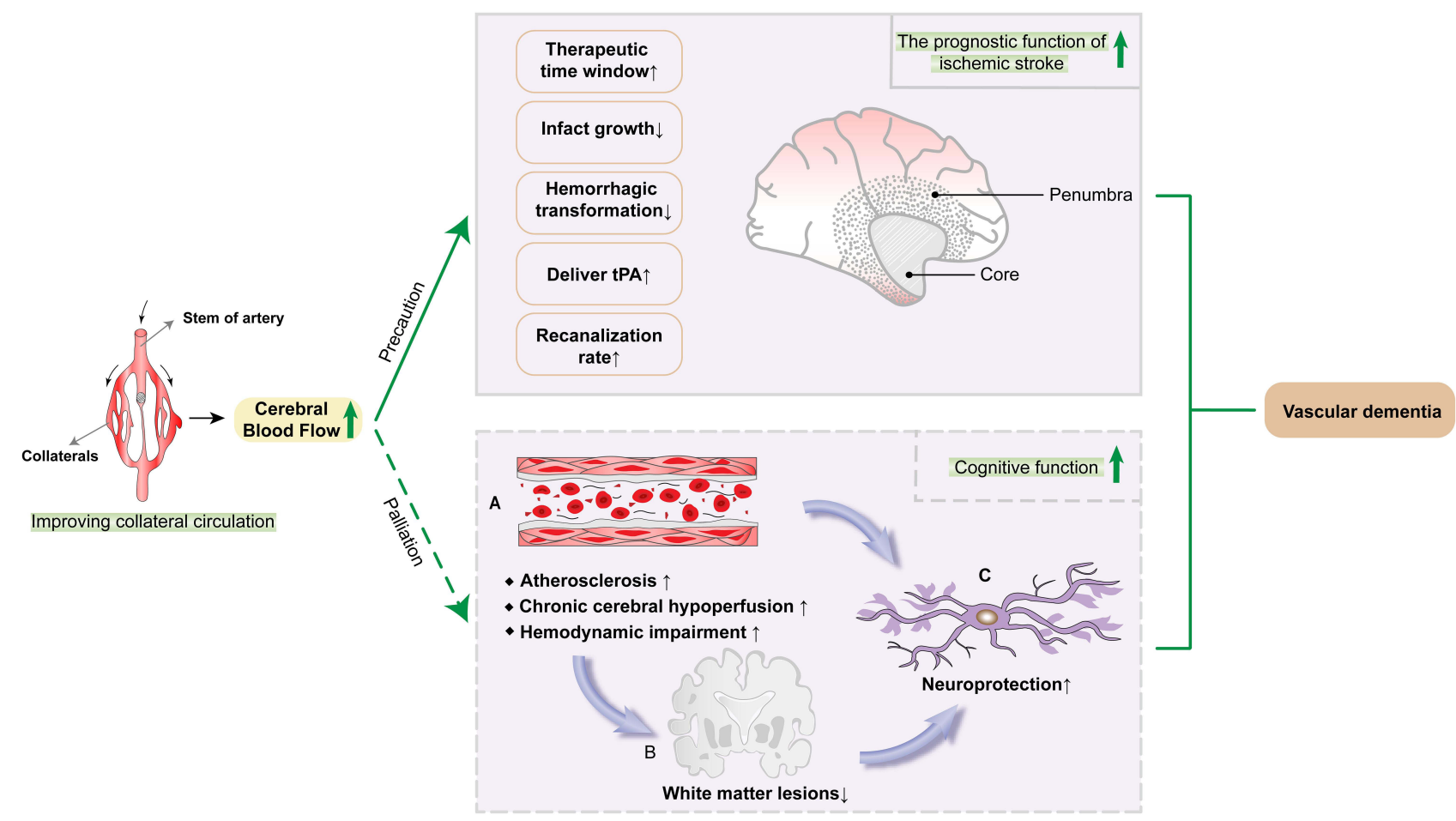

Figure I Improving collateral circulation contributes to preventing or slowing the progression of vascular dementia (VaD). On the one hand, improving collateral circulation can prevent $\mathrm{VaD}$ via compensating cerebral blood flow and enhancing the prognostic function of ischemic stroke, which involves prolonging the reperfusion treatment time window, reducing the infarct core volume, decreasing the risk of hemorrhagic transformation, delivering more tissue plasminogen activator, and increasing recanalization rate. On the other hand, enhancing collateral circulation can compensate cerebral blood flow to eliminate the adverse effects of atherosclerosis, chronic cerebral hypoperfusion and hemodynamic disorders, reduce white matter lesions, protect neurons, improve cognitive function, and slow the progression of VaD. 


\section{Conclusions and Perspectives}

Collateral enhancement may not only prolong the reperfusion treatment time window of IS but also improve the therapeutic effect of thrombolytic drugs or intravascular intervention, thereby reducing the risk of IS developing into $\mathrm{VaD}$; it may also reduce the contribution of atherosclerosis, $\mathrm{CCH}$, hemodynamic damage, WM changes, and cognitive dysfunction to VaD (Figure 1). At present, some pharmacological or non-pharmacological interventions have also been developed to improve collateral circulation, such as inhaled nitric oxide, ${ }^{66}$ statins pretreatment, ${ }^{67}$ TAO $^{68}$ and RIPC. ${ }^{69}$ At the same time, the discovery of related targets that promote collateral circulation or induce natural collateral remodeling (eg endocan ${ }^{70}$ and $\mathrm{PEDF}^{71}$ ) has expanded the range of strategies to enhance collateral circulation. Considering the chronic development time frame of $\mathrm{VaD}$, efforts are also needed to explore more collateral improvement strategies. More importantly, it is necessary to carefully design reasonable and rigorous trials to determine the contribution threshold of improving collateral circulation combined with other neuroprotective strategies to prevent and slow the progression of $\mathrm{VaD}$.

\section{Abbreviations}

$\mathrm{VaD}$, vascular dementia; $\mathrm{CBF}$, cerebral blood flow; $\mathrm{CCH}$, chronic cerebral hypoperfusion; WM, white matter; IS, ischemic stroke; SVD, small vessel diseases; WMH, white matter hyperintensities; LA, leukoaraiosis; TAO, transient aortic occlusion; RIPC, remote ischemic postconditioning; PEDF, pigment epithelium-derived factor.

\section{Author Contributions}

All authors made a significant contribution to the work reported, whether that is in the conception, study design, execution, acquisition of data, analysis and interpretation, or in all these areas; took part in drafting, revising or critically reviewing the article; gave final approval of the version to be published; have agreed on the journal to which the article has been submitted; and agree to be accountable for all aspects of the work.

\section{Funding}

We are grateful for the financial support from the National Natural Science Foundation of China (No. 81804028, $81503279)$ and the Natural Science Foundation of Tianjin (18JCQNJC83400).

\section{Disclosure}

The authors declare that they have no competing interests.

\section{References}

1. Aggarwal NT, Decarli C. Vascular dementia: emerging trends. Semin Neurol. 2007;27(1):66-77. doi:10.1055/s-2006-956757

2. Wolters FJ, Ikram MA. Epidemiology of vascular dementia. Arterioscler Thromb Vasc Biol. 2019;39(8):1542-1549. doi:10.1161/ ATVBAHA.119.311908

3. Khan A, Kalaria RN, Corbett A, Ballard C. Update on vascular dementia. J Geriatr Psychiatry Neurol. 2016;29(5):281-301. doi:10.1177/0891988716654987

4. Smith KJ, Ainslie PN. Regulation of cerebral blood flow and metabolism during exercise. Exp Physiol. 2017;102(11):1356-1371. doi:10.1113/EP086249

5. Parfenov VA, Ostroumova OD, Ostroumova TM, et al. Vascular cognitive impairment: pathophysiological mechanisms, insights into structural basis, and perspectives in specific treatments. Neuropsychiatr Dis Treat. 2019;15:1381-1402. doi:10.2147/NDT.S197032

6. Harris JJ, Jolivet R, Attwell D. Synaptic energy use and supply. Neuron. 2012;75(5):762-777. doi:10.1016/j.neuron.2012.08.019

7. Iadecola C. Neurovascular regulation in the normal brain and in Alzheimer's disease. Nat Rev Neurosci. 2004;5(5):347-360. doi: $10.1038 / \mathrm{nrn} 1387$

8. Liu H, Zhang J. Cerebral hypoperfusion and cognitive impairment: the pathogenic role of vascular oxidative stress. Int J Neurosci. 2012;122(9):494-499. doi:10.3109/00207454.2012.686543

9. Toda N. Age-related changes in endothelial function and blood flow regulation. Pharmacol Ther. 2012;133(2):159-176.

10. Venkat P, Chopp M, Chen J. Models and mechanisms of vascular dementia. Exp Neurol. 2015;272:97-108. doi:10.1016/j. expneurol.2015.05.006

11. Sabayan B, Jansen S, Oleksik AM, et al. Cerebrovascular hemodynamics in Alzheimer's disease and vascular dementia: a metaanalysis of transcranial Doppler studies. Ageing Res Rev. 2012;11 (2):271-277. doi:10.1016/j.arr.2011.12.009

12. Liebeskind DS. Collateral circulation. Stroke. 2003;34(9):2279-2284. doi:10.1161/01.STR.0000086465.41263.06

13. Luo C, Liang F, Ren H, et al. Collateral blood flow in different cerebrovascular hierarchy provides endogenous protection in cerebral ischemia. Brain Pathol. 2017;27(6):809-821. doi:10.1111/bpa.12458

14. Ginsberg MD. Expanding the concept of neuroprotection for acute ischemic stroke: the pivotal roles of reperfusion and the collateral circulation. Prog Neurobiol. 2016;145-146:46-77.

15. Kitagawa K, Saitoh M, Ishizuka K, Shimizu S. Remote limb ischemic conditioning during cerebral ischemia reduces infarct size through enhanced collateral circulation in murine focal cerebral ischemia. J Stroke Cerebrovasc Dis. 2018;27(4):831-838. doi:10.1016/j. jstrokecerebrovasdis.2017.09.068

16. Ginsberg MD. The cerebral collateral circulation: relevance to pathophysiology and treatment of stroke. Neuropharmacology. 2018;134 (Pt B):280-292. doi:10.1016/j.neuropharm.2017.08.003

17. Levine DA, Kabeto M, Langa KM, Lisabeth LD, Rogers MA, Galecki AT. Does stroke contribute to racial differences in cognitive decline? Stroke. 2015;46(7):1897-1902. doi:10.1161/ STROKEAHA.114.008156

18. Jung S, Wiest R, Gralla J, McKinley R, Mattle H, Liebeskind D. Relevance of the cerebral collateral circulation in ischaemic stroke: time is brain, but collaterals set the pace. Swiss Med Wkly. 2017. doi:10.4414/smw.2017.14538

19. Troidl K, Schaper W. Arteriogenesis versus angiogenesis in peripheral artery disease. Diabetes Metab Res Rev. 2012;28(Suppl 1):27-29. doi:10.1002/dmrr.2232 
20. Liu LP, Xu AD, Wong LKS, Wang DZ, Wang YJ. Chinese consensus statement on the evaluation and intervention of collateral circulation for ischemic stroke. CNS Neurosci Ther. 2014;20(3):202-208. doi:10.1111/cns. 12226

21. Okahara M, Kiyosue H, Mori H, Tanoue S, Sainou M, Nagatomi H. Anatomic variations of the cerebral arteries and their embryology: a pictorial review. Eur Radiol. 2002;12(10):2548-2561. doi:10.1007/ s00330-001-1286-x

22. Martinon E, Lefevre PH, Thouant P, Osseby GV, Ricolfi F, Chavent A. Collateral circulation in acute stroke: assessing methods and impact: a literature review. $J$ Neuroradiol. 2014;41(2):97-107. doi:10.1016/j.neurad.2014.02.001

23. Nishijima Y, Akamatsu Y, Weinstein PR, Liu J. Collaterals: implications in cerebral ischemic diseases and therapeutic interventions. Brain Res. 2015;1623:18-29. doi:10.1016/j. brainres.2015.03.006

24. Knopman DS. Cerebrovascular disease and dementia. $\mathrm{Br} J$ Radiol. 2007;80 Spec No 2:S121-127. doi:10.1259/bjr/75681080

25. Ihle-Hansen H, Ihle-Hansen H, Sandset E, Hagberg G. Subclinical carotid artery atherosclerosis and cognitive function: a mini-review. Front Neurol. 2021;12:705043.

26. Balestrini S, Perozzi C, Altamura C, et al. Severe carotid stenosis and impaired cerebral hemodynamics can influence cognitive deterioration. Neurology. 2013;80(23):2145-2150.

27. Gong L, Wang H, Dong Q, et al. Intracranial atherosclerotic stenosis is related to post-stroke cognitive impairment: a cross-sectional study of minor stroke. Curr Alzheimer Res. 2020;17(2):177-184.

28. Liebeskind DS, Cotsonis GA, Saver JL, Lynn MJ, Cloft HJ, Chimowitz MI. Collateral circulation in symptomatic intracranial atherosclerosis. J Cereb Blood Flow Metab. 2010;31(5):1293-1301. doi: $10.1038 / \mathrm{jcbfm} .2010 .224$

29. Lau AY, Wong EH, Wong A, Mok VC, Leung TW, Wong KS. Significance of good collateral compensation in symptomatic intracranial atherosclerosis. Cerebrovasc Dis. 2012;33(6):517-524. doi: $10.1159 / 000337332$

30. Duncombe J, Kitamura A, Hase Y, Ihara M, Kalaria RN, Horsburgh K. Chronic cerebral hypoperfusion: a key mechanism leading to vascular cognitive impairment and dementia. Closing the translational gap between rodent models and human vascular cognitive impairment and dementia. Clin Sci. 2017;131(19):2451-2468. doi:10.1042/CS20160727

31. Daulatzai MA. Cerebral hypoperfusion and glucose hypometabolism: key pathophysiological modulators promote neurodegeneration, cognitive impairment, and Alzheimer's disease. J Neurosci Res. 2017;95 (4):943-972.

32. Jing Z, Shi C, Zhu L, et al. Chronic cerebral hypoperfusion induces vascular plasticity and hemodynamics but also neuronal degeneration and cognitive impairment. J Cereb Blood Flow Metab. 2015;35 (8):1249-1259. doi:10.1038/jcbfm.2015.55

33. Omura-Matsuoka E, Yagita Y, Sasaki T, et al. Hypertension impairs leptomeningeal collateral growth after common carotid artery occlusion: restoration by antihypertensive treatment. $J$ Neurosci Res. 2011;89(1):108-116. doi:10.1002/jnr.22522

34. Guglielmi V, LeCouffe NE, Zinkstok SM, et al. Collateral circulation and outcome in atherosclerotic versus cardioembolic cerebral large vessel occlusion. Stroke. 2019;50(12):3360-3368. doi:10.1161/ STROKEAHA.119.026299

35. Rebello LC, Bouslama M, Haussen DC, et al. Stroke etiology and collaterals: atheroembolic strokes have greater collateral recruitment than cardioembolic strokes. Eur J Neurol. 2017;24(6):762-767. doi:10.1111/ene. 13287

36. Lin T, Lai Z, Lv Y, et al. Effective collateral circulation may indicate improved perfusion territory restoration after carotid endarterectomy. Eur Radiol. 2017;28(2):727-735. doi:10.1007/s00330-017-5020-8
37. Stefani A, Sancesario G, Pierantozzi M, et al. CSF biomarkers, impairment of cerebral hemodynamics and degree of cognitive decline in Alzheimer's and mixed dementia. J Neurol Sci. 2009;283 (1-2):109-115. doi:10.1016/j.jns.2009.02.343

38. Kluytmans M, van der Grond J, van Everdingen K, Klijn C, Kappelle L, Viergever M. Cerebral hemodynamics in relation to patterns of collateral flow. Stroke. 1999;30(7):1432-1439.

39. Liu X, Dornbos D, Pu Y, et al. Collateral circulation alters downstream hemodynamic stress caused by intracranial atherosclerotic stenosis. Neurol Res. 2017;39(6):498-503. doi:10.1080/ 01616412.2017.1315483

40. Derdeyn C, Videen T, Fritsch S, Carpenter D, Grubb R, Powers WJ. Compensatory mechanisms for chronic cerebral hypoperfusion in patients with carotid occlusion. Stroke. 1999;30 (5):1019-1024.

41. Hase Y, Horsburgh K, Ihara M, Kalaria RN. White matter degeneration in vascular and other ageing-related dementias. $J$ Neurochem. 2018;144(5):617-633. doi:10.1111/jnc.14271

42. Ihara M, Polvikoski TM, Hall R, et al. Quantification of myelin loss in frontal lobe white matter in vascular dementia, Alzheimer's disease, and dementia with Lewy bodies. Acta Neuropathol. 2010;119 (5):579-589. doi:10.1007/s00401-009-0635-8

43. Kalaria RN. Neuropathological diagnosis of vascular cognitive impairment and vascular dementia with implications for Alzheimer's disease. Acta Neuropathol. 2016;131(5):659-685. doi:10.1007/s00401-016-1571-z

44. Soria G, Tudela R, Marquez-Martin A, et al. The ins and outs of the BCCAo model for chronic hypoperfusion: a multimodal and longitudinal MRI approach. PLoS One. 2013;8(9):e74631. doi:10.1371/ journal.pone. 0074631

45. Lin MP, Brott TG, Liebeskind DS, Meschia JF, Sam K, Gottesman RF. Collateral recruitment is impaired by cerebral small vessel disease. Stroke. 2020;51(5):1404-1410. doi:10.1161/ STROKEAHA.119.027661

46. Kobari M, Meyer J, Ichijo M, Oravez W. Leukoaraiosis: correlation of MR and CT findings with blood flow, atrophy, and cognition. Am J Neuroradiol. 1990;11(2):273-281.

47. Giurgiutiu DV, Yoo AJ, Fitzpatrick K, et al. Severity of leukoaraiosis, leptomeningeal collaterals, and clinical outcomes after intra-arterial therapy in patients with acute ischemic stroke. J Neurointerv Surg. 2015;7(5):326-330. doi:10.1136/neurintsurg-2013-011083

48. Korczyn AD, Vakhapova V, Grinberg LT. Vascular dementia. J Neurol Sci. 2012;322(1-2):2-10. doi:10.1016/j.jns.2012.03.027

49. Ogoh S. Relationship between cognitive function and regulation of cerebral blood flow. J Physiol Sci. 2017;67(3):345-351. doi:10.1007/ s12576-017-0525-0

50. Sztriha L, Nemeth D, Sefcsik T, Vecsei L. Carotid stenosis and the cognitive function. J Neurol Sci. 2009;283:36-40.

51. Everts R, Wapp M, Burren Y, et al. Cognitive and emotional effects of carotid stenosis. Swiss Med Weekly. 2014;144:w13970.

52. Xie X, Lu W, Chen Y, et al. Prostaglandin E1 alleviates cognitive dysfunction in chronic cerebral hypoperfusion rats by improving hemodynamics. Front Neurosci. 2019;13:549. doi:10.3389/fnins.2019.00549

53. Khan MB, Hafez S, Hoda MN, et al. Chronic remote ischemic conditioning is cerebroprotective and induces vascular remodeling in a VCID model. Transl Stroke Res. 2018;9(1):51-63. doi:10.1007/ s12975-017-0555-1

54. Meng Y, Yu K, Zhang L, Liu Y. Cognitive decline in asymptomatic middle cerebral artery stenosis patients with moderate and poor collaterals: a 2-year follow-up study. Med Sci Monit. 2019;25:4051-4058. doi:10.12659/MSM.913797

55. Wei W, Yi X, Ruan J, Duan X, Luo H, Lv Z. Influence of collateral circulation on cerebral blood flow and frontal lobe cognitive function in patients with severe internal carotid artery stenosis. BMC Neurol. 2019;19(1):151. doi:10.1186/s12883-019-1380-9 
56. Alvarez-Sabin J, Roman GC. Citicoline in vascular cognitive impairment and vascular dementia after stroke. Stroke. 2011;42(1 Suppl): S40-43. doi:10.1161/STROKEAHA.110.606509

57. Vijayan M, Kumar S, Bhatti JS, Reddy PH. Molecular links and biomarkers of stroke, vascular dementia, and alzheimer's disease. Prog Mol Biol Transl Sci. 2017;146:95-126.

58. Kalaria RN, Akinyemi R, Ihara M. Stroke injury, cognitive impairment and vascular dementia. Biochim Biophys Acta. 2016;1862 (5):915-925. doi:10.1016/j.bbadis.2016.01.015

59. Jung S, Gilgen M, Slotboom J, et al. Factors that determine penumbral tissue loss in acute ischaemic stroke. Brain. 2013;136(Pt 12):3554-3560. doi:10.1093/brain/awt246

60. Macchi C, Miniati B, Zito A, et al. Collateral circulation in internal carotid artery occlusion. A study by duplex scan and magnetic resonance angiography. Minerva Cardioangiologica. 2002;50 (6):695-700.

61. Seyman E, Shaim H, Shenhar-Tsarfaty S, Jonash-Kimchi T, Bornstein NM, Hallevi $\mathrm{H}$. The collateral circulation determines cortical infarct volume in anterior circulation ischemic stroke. $B M C$ Neurol. 2016;16(1):206. doi:10.1186/s12883-016-0722-0

62. Bang OY, Saver JL, Buck BH, et al. Impact of collateral flow on tissue fate in acute ischaemic stroke. J Neurol Neurosurg Psychiatry. 2008;79(6):625-629. doi:10.1136/jnnp.2007.132100

63. Piedade GS, Schirmer CM, Goren O, et al. Cerebral collateral circulation: a review in the context of ischemic stroke and mechanical thrombectomy. World Neurosurg. 2019;122:33-42. doi:10.1016/j. wneu.2018.10.066

64. Khatri R, Vellipuram AR, Maud A, Cruz-Flores S, Rodriguez GJ. Current endovascular approach to the management of acute ischemic stroke. Curr Cardiol Rep. 2018;20(6). doi:10.1007/ s11886-018-0989-4
65. Martinez-Vila E, Murie-Fernandez M, Gallego Perez-Larraya J, Irimia P. Neuroprotection in vascular dementia. Cerebrovasc Dis. 2006;21(Suppl 2):106-117. doi:10.1159/000091710

66. Terpolilli NA, Kim SW, Thal SC, et al. Inhalation of nitric oxide prevents ischemic brain damage in experimental stroke by selective dilatation of collateral arterioles. Circ Res. 2012;110(5):727-738. doi:10.1161/CIRCRESAHA.111.253419

67. Malhotra K, Safouris A, Goyal N, et al. Association of statin pretreatment with collateral circulation and final infarct volume in acute ischemic stroke patients: a meta-analysis. Atherosclerosis. 2019;282:75-79. doi:10.1016/j.atherosclerosis.2019.01.006

68. Ramakrishnan G, Dong B, Todd KG, Shuaib A, Winship IR. Transient aortic occlusion augments collateral blood flow and reduces mortality during severe ischemia due to proximal middle cerebral artery occlusion. Transl Stroke Res. 2016;7(2):149-155. doi:10.1007/ s12975-015-0443-5

69. Zhang Y, Ma L, Ren C, et al. Immediate remote ischemic postconditioning reduces cerebral damage in ischemic stroke mice by enhancing leptomeningeal collateral circulation. J Cell Physiol. 2019;234 (8):12637-12645. doi:10.1002/jcp. 27858

70. Emet S, Elitok A, Onur I, et al. Endocan: a novel biomarker associated with well-developed coronary collateral circulation in patients with stable angina and chronic total occlusion. $J$ Thromb Thrombolysis. 2017;43(1):60-67. doi:10.1007/s11239-016-1424-6

71. Liu X, Liu Z, Chen J, et al. Pigment epithelium-derived factor increases native collateral blood flow to improve cardiac function and induce ventricular remodeling after acute myocardial infarction. J Am Heart Assoc. 2019;8(22):e013323. doi:10.1161/JAHA.119. 013323
Neuropsychiatric Disease and Treatment

\section{Publish your work in this journal}

Neuropsychiatric Disease and Treatment is an international, peerreviewed journal of clinical therapeutics and pharmacology focusing on concise rapid reporting of clinical or pre-clinical studies on a range of neuropsychiatric and neurological disorders. This journal is indexed on PubMed Central, the 'PsycINFO' database and CAS, and is the official journal of The International Neuropsychiatric Association (INA). The manuscript management system is completely online and includes a very quick and fair peer-review system, which is all easy to use. Visit http://www.dovepress.com/testimonials.php to read real quotes from published authors. 